\title{
Lipid hydroperoxide, an intermediate product of oxidative stress, induces tumour progression-associated genes in hepatocarcinoma cells
}

\author{
Nataliya Rohr-Udilova*1, Klaus Stolze², Bettina Grasl-Kraupp ${ }^{3}$, Rolf Schulte- \\ Hermann ${ }^{3}$ and Markus Peck-Radosavljevic ${ }^{1}$
}

Address: ${ }^{1}$ Division of Hepatology and Gastroenterology, Department of Medicine III, Medical University of Vienna, Austria, ${ }^{2}$ Department of Natural Science, Veterinary University of Vienna, Austria and ${ }^{3}$ Institute of Cancer Research, Department of Medicine I, Medical University of Vienna, Austria

Email: Nataliya Rohr-Udilova* - nataliya.rohr-udilova@meduniwien.ac.at

* Corresponding author

\author{
from 13th Scientific Symposium of the Austrian Pharmacological Society (APHAR). Joint Meeting with the Austrian Society of Toxicology (ASTOX) and the \\ Hungarian Society for Experimental and Clinical Pharmacology (MFT) \\ Vienna, Austria. 22-24 November 2007 \\ Published: I4 November 2007 \\ BMC Pharmacology 2007, 7(Suppl 2):A67 doi:10.1 186/147I-2210-7-S2-A67
}

This abstract is available from: http://www.biomedcentral.com/I47I-22/0/7/S2/A67

(c) 2007 Rohr-Udilova et al; licensee BioMed Central Ltd.

Hepatocellular carcinoma often develops in the liver under chronic inflammation. Oxygen radicals, produced during inflammation, attack membrane lipids and form a number of oxidized metabolites including lipid hydroperoxides. The addition of linoleic acid hydroperoxide (LOOH) to the medium of recently established human hepatocarcinoma cell line (HCC-1.2) caused dosedependent cell loss and enhanced LDH-release. Under subtoxic conditions LOOH induced intracellular hydrogen peroxide production and a decrease of cellular GSH content. Elevated expression of protooncogene c-myc and a catalytic subunit of telomerase hTERT were observed under $\mathrm{LOOH}$ exposure. Myc activation is sufficient to induce cell cycle entry in the absence of growth factors. Accordingly, the cells were pushed into the S- and $\mathrm{G}_{2} / \mathrm{M}$ phase by LOOH. An increased expression of c-fos, $\mathrm{c}$-jun, the antiapoptotic enzyme heme oxygenase $1(\mathrm{HO}-1)$ and the proinflammatory angiogenic interleukin-8 (IL-8) was detected under LOOH exposure. Pre-treatment of cells with antioxidant $\mathrm{N}$-acetylcystein or with selenite, which induces the LOOH-detoxifying enzyme glutathione peroxidase, partially inhibited the expression of LOOHinduced genes implicating the involvement of oxidative stress. Application of SnPPIX, a HO-1 inhibitor, decreased the viability of HCC-1.2 cells indicating the protective role of HO-1 induction. These results show that lipid hydroperoxides may be an important driving force for carcinogenesis in the liver. 